\title{
COMUNICATION INTERFACE PROTOTYPE USED FOR DATA TRANSMISSION AT ELECTRIC SYSTEMS
}

\author{
Mihaela Dorica STROIA*, Dorian ANGHEL**, Dănuţ-Eugeniu MOȘTEANU***, \\ Cornel HAȚIEGAN*
}

\author{
*University "Eftimie Murgu”, Reșița, Romania \\ **University Politehnica, Bucharest, Romania \\ ****Nicolae Bălcescu" Land Forces Academy, Sibiu, Romania \\ m.stroia@uem.ro, dorian.anghel@yahoo.com,dmosteanu@gmail.com, \\ c.hatiegan@uem.ro
}

\begin{abstract}
Present paper presents design, build-up and testing of a communication interface used for data transmission at an electric system. The communication interface is a Serial Port Controller (SPC)RS485/RS422 and is part of a system used for monitoring electric parameters of a high power synchronous engine. Its main function is to collect information from analyser and bridge rectifier and to pass it to programmable logic controller and to display unit. TheRSx interface was designed using software Eagle 8.0.1 and its programming was made using software FlowCode 8. Physical and logical test results will be shown.
\end{abstract}

Keywords: data transmission, serial port controller, synchronous drive, keywords

\section{Introduction}

In present paper is described a communication interface prototype integrated in a system used for monitoring electrical parameters of high power synchronous engine. System components are connected to a serial electrical network 485, using MODBUS RTU protocol. System consists of six numerical displays connected to a network analyser CVM96, a bridge rectifier DCREG2, a programmable logic controller (PLC) and the serial port controller RS485/RS422, all in a parallel connection to serial network 485 . To each component was associated a numerical identification, values from 1 to 9 .

\section{Designing and Programming SPC Interface}

As mentioned, communication interface prototype is a serial port controller, SPC RS485/RS422, connected to an electrical parameter monitoring system. Measured electrical parameters are engine voltage and electric current, real power and reactive power transmitted to and from CVM96 analyser, excitation voltage and excitation current collected from bridge rectifier. In a usual connection parametric values were transmitted to PLC for analysing, decision making according results and sending values to numerical display unit [1-3]. Communication interface main role is to take over some of the tasks of PLC, such as: retrieves data from analyser and rectifier, transmits them to PLC, for analysing and decisions, and to display unit [4-7].

Architectural design of monitoring system is reflected in figure 1. Communication interface SPC can function in master or slave mode. For this case study SPC was set to master mode, all other components functioning in slave mode. 


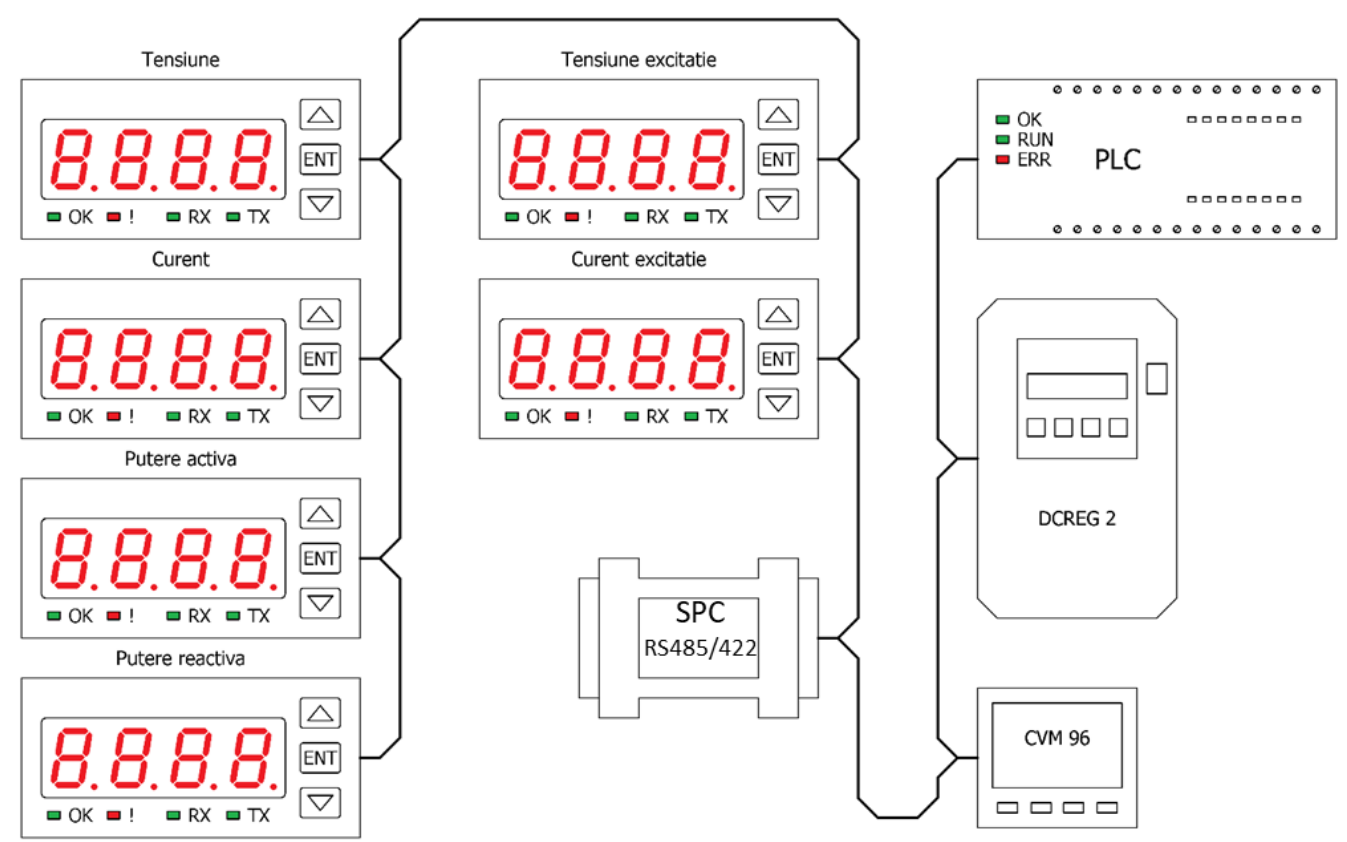

Figure 1: Architectural design of monitoring system

SPC design was made using software AutoDeskEAGLE 8.0.1., a scriptable electronic design automation software which has embedded schematic editor module, structure module and multi- threaded auto router module, all in a single programme, allowing designing circuits diagrams [8]. Using electrical circuit scheme from figure 2 we designed SPC's circuit board model shown in figure 3 .

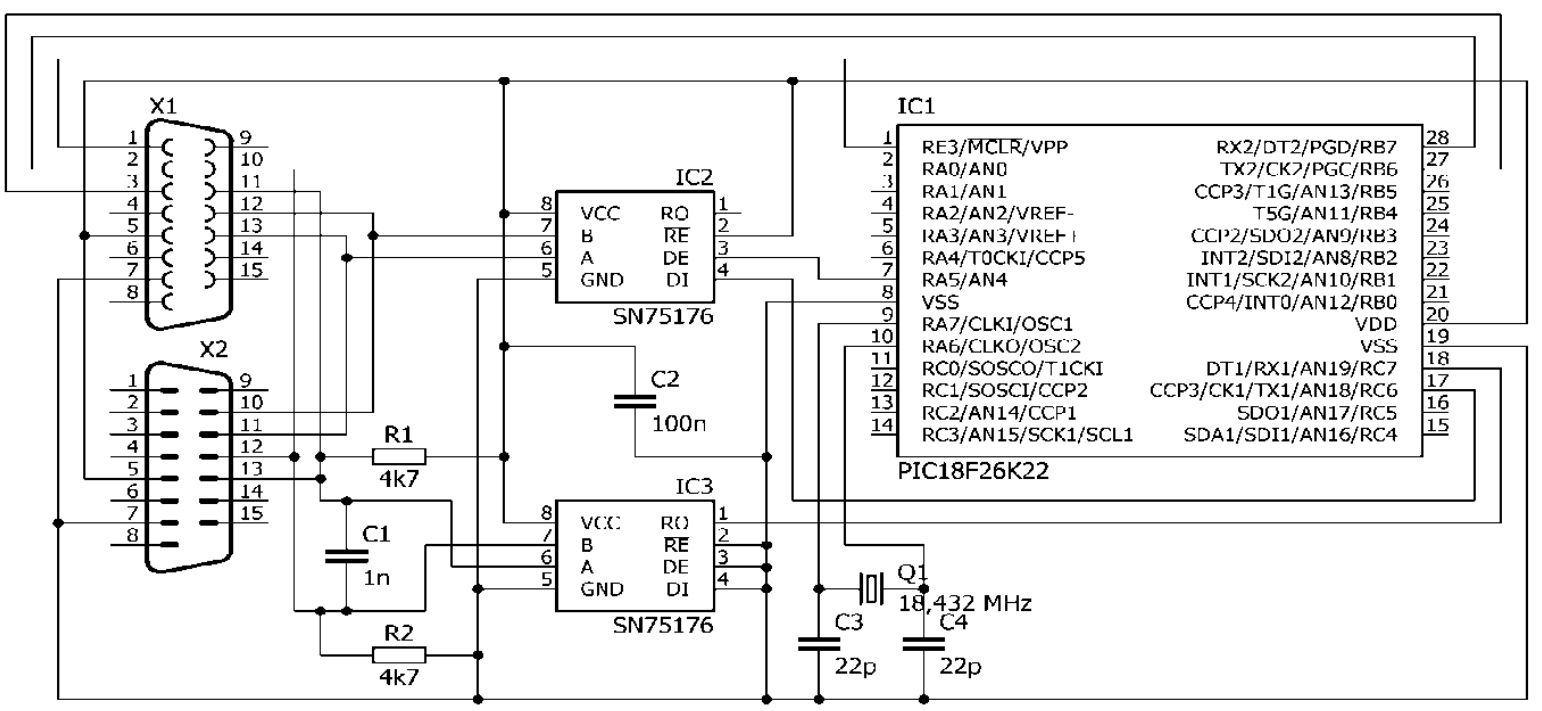

Figure 2: Electrical circuit scheme of SPC 


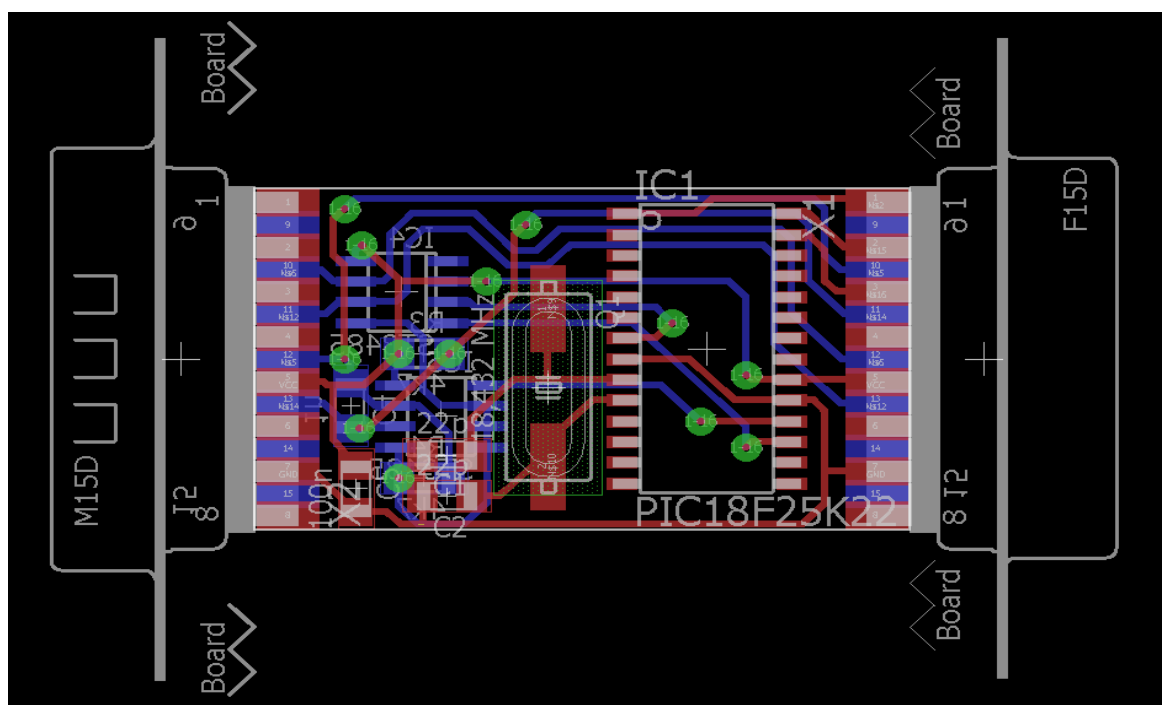

Figure 3: Design of circuit board of SPC

For programming PIC microcontroller of SPC FlowCode8 was used. FlowCode8 is an advanced integrated development environment (IDE) for electronic and electromechanical developmenttargeted microcontrollers, using a flowchart language, pseudocode or C code $[9,10]$.

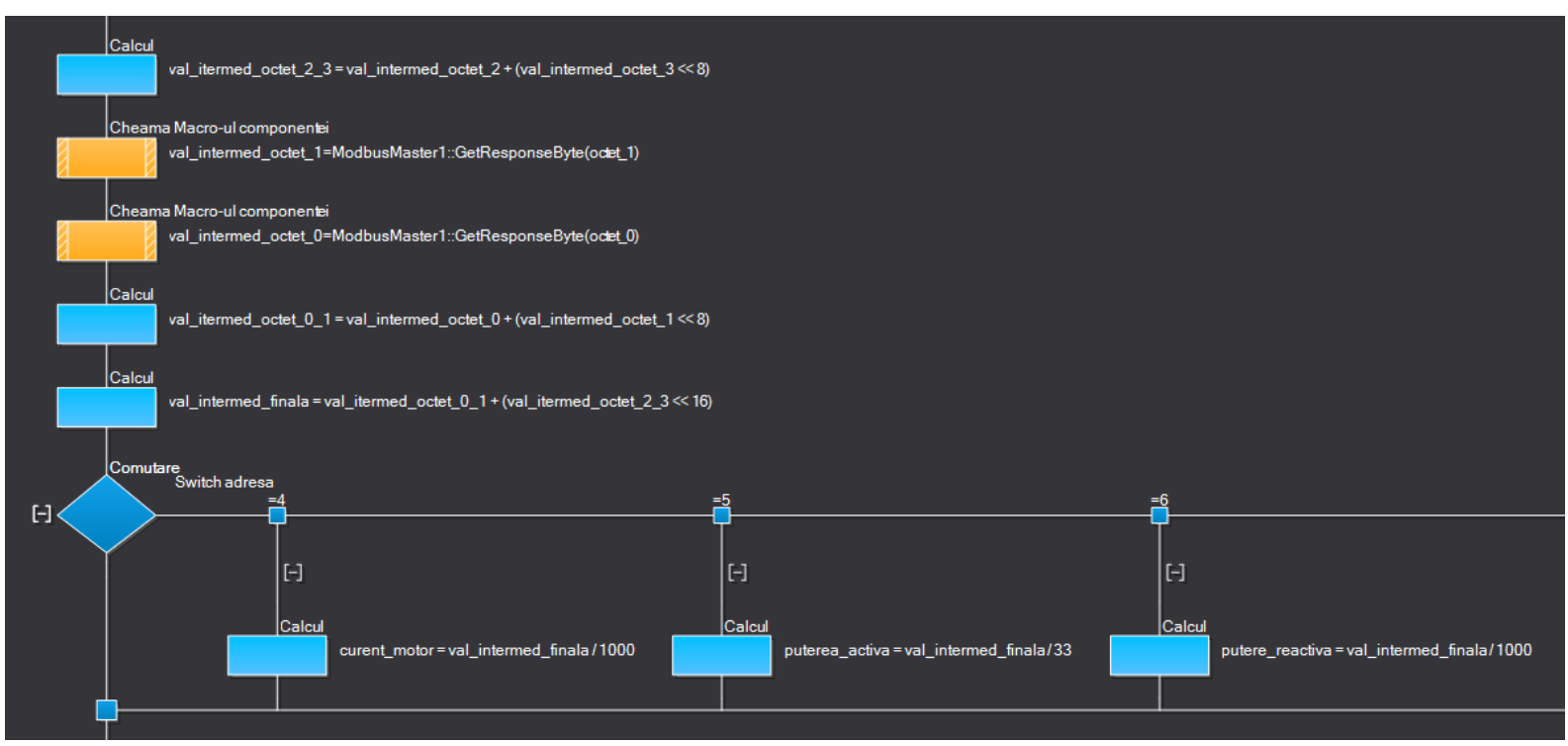

Figure 4: Flowchart for reading data from analyser

Figure 4 represents FlowCode8 programming flowchart procedure for reading parametric values from analyser. Analyser transmits binary data starting with less significant bit of binary sequence, therefore it is imposed shifting binary sequence. According to obtained binary address data conversion will be made, specific to each numerical display. The $\mathrm{C}$ code of reading procedure flowchart is pictured in figure 5 . 


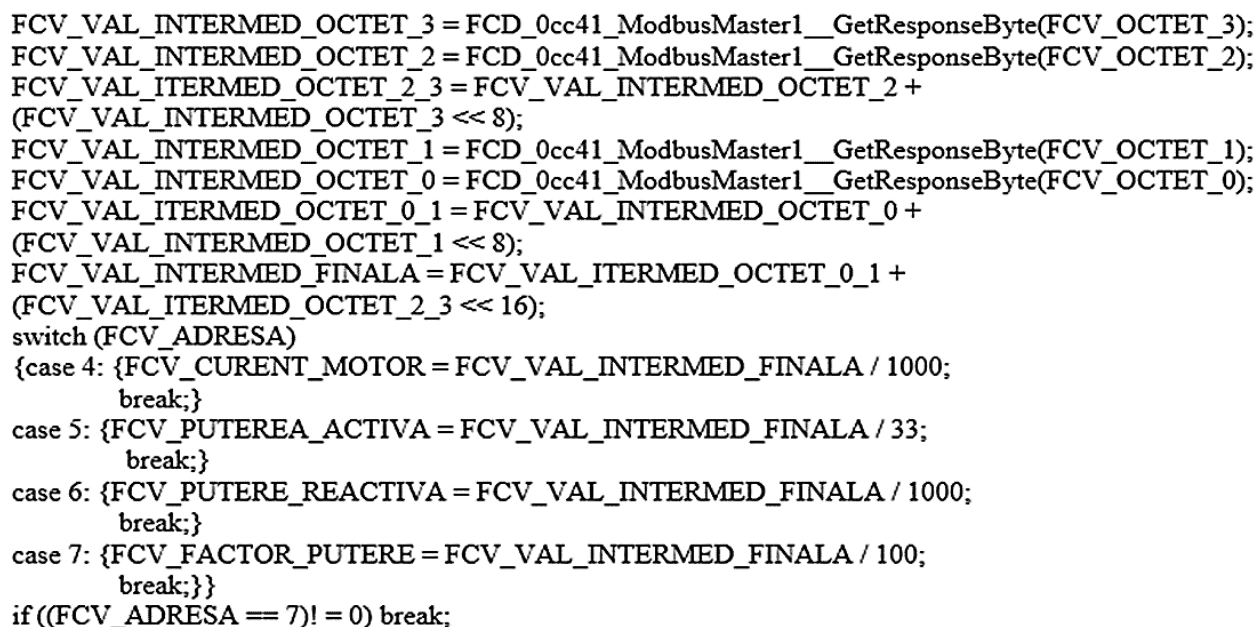

Figure 5: C programming code for reading data from analyser

Flowchart sequence for data writing, illustrated in figure 6 , is used to determine to which numerical display should data be sent to, after obtaining the identifications sends data to display unit.

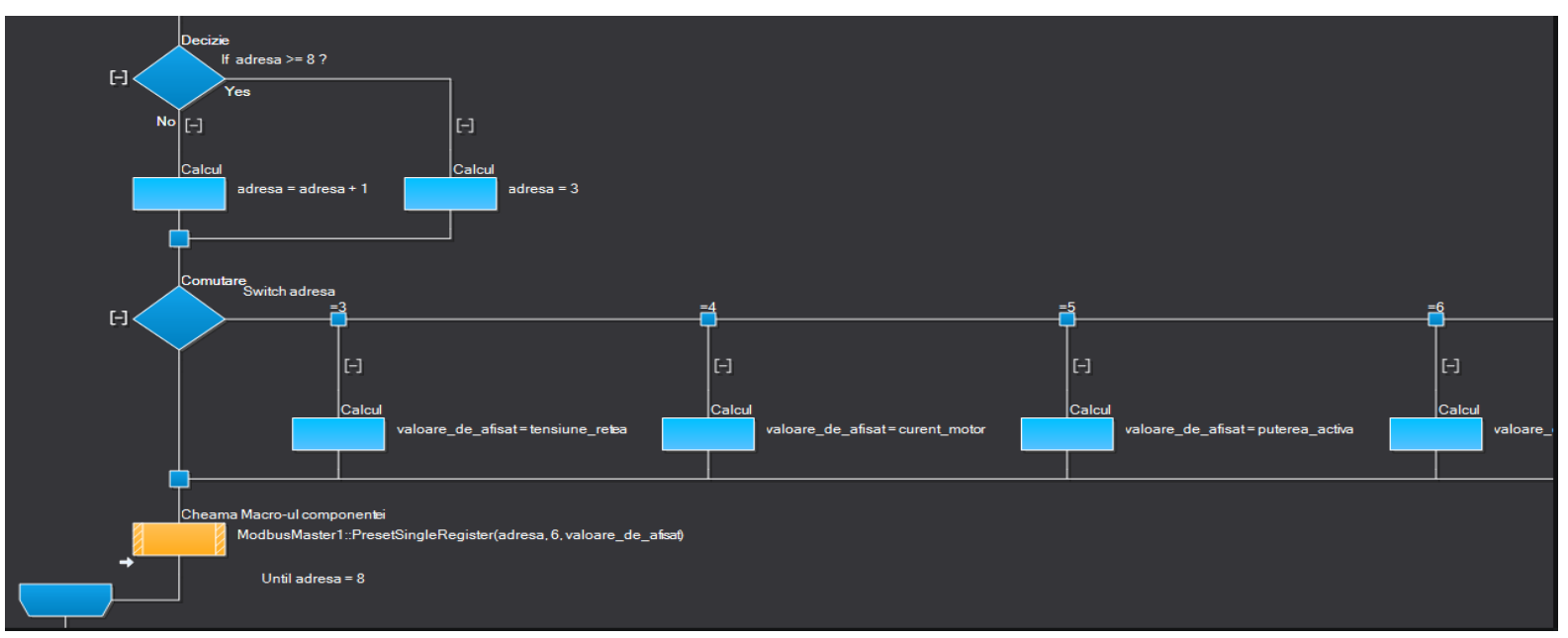

Figure 6: Flowchart for writing data to display unit

\section{Build-Up of SPC Interface and Test Results}

For build-up SPC communication interface shown in figure 7 , on circuit board was integrated a PIC18F26K22 microcontroller, two $75176 \mathrm{~B}$ drivers, a quartz oscillator of $18.432 \mathrm{MHz}$ with a low error risk, two $22 \mathrm{pF}$ capacitors, a $100 \mathrm{nF}$ capacitor, a $1 \mathrm{nF}$ capacitor and two resistances of $4.7 \mathrm{~K} \Omega$. $\mathrm{SPC}$ is powered at $5 \mathrm{~V}$ by an external power supply source.

PIC18F26K22 microcontroller has a RISC architecture with following features: up to $1 \mathrm{~KB}$ data EEPROM, 64KB memory addressing, up to 16 MIPS operation, 16bits wide instructions, 8bits wide data path, priority levels for interrupts, $16 \mathrm{MHz}$ internal oscillator, ADC and DAC modules, is self-programmable, high/low voltage detection module $[11,12]$. 

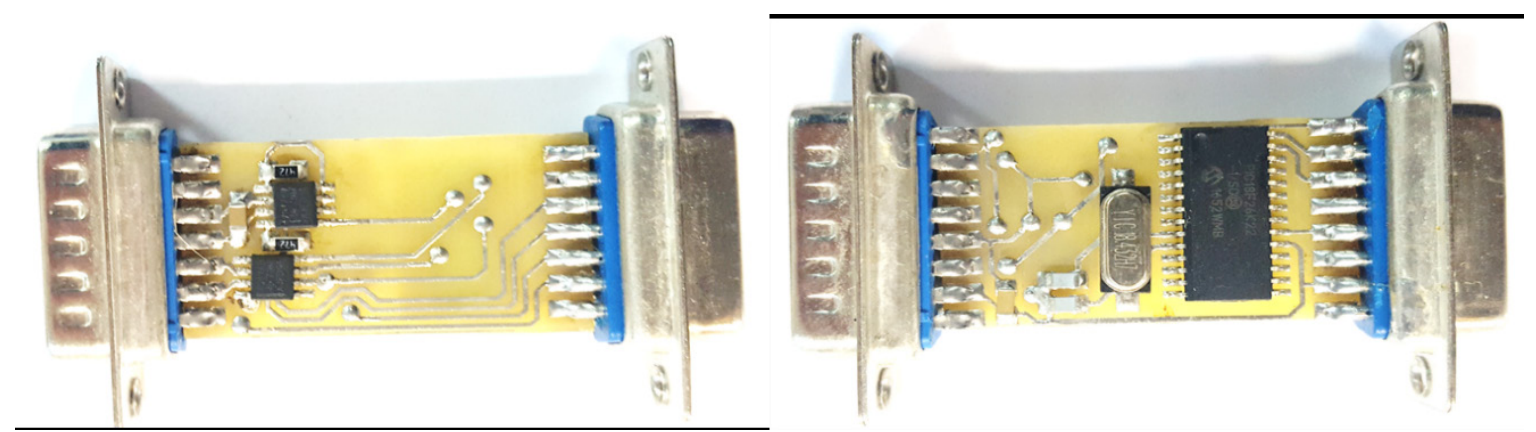

Figure 7: SPC communication interface

The 75176B drivers are integrated circuits designed for bidirectional data communication on multipoint bus transmission lines. Driver has three state differential line driver and one differential input line receiver with active-high and active-low enables, outputs and inputs are connected internally to $\mathrm{I} / \mathrm{O}$ bus ports in order to assure minimum loading to the bus when the driver is disabled $[13,14]$.

Test functioning results can be seen in figure 8 a) and b). Image 8.a) consists of system panel containing numerical displays for parametric values monitoring where it can be noticed in the upper side of panel values for synchronous engine voltage, electrical current, real power, reactive power, and in the lower side of the panel values for excitation voltage and excitation current collected from bridge rectifier.Image 8.b) points out the way data, as addresses, is transmitted between system components. We recall that each component has a system identifier, represented, in this example by the first set of characters in each code line: 01 for programmable controller, 02 for analyser, 03-08 for numerical displays, 09 for SPC communication interface.

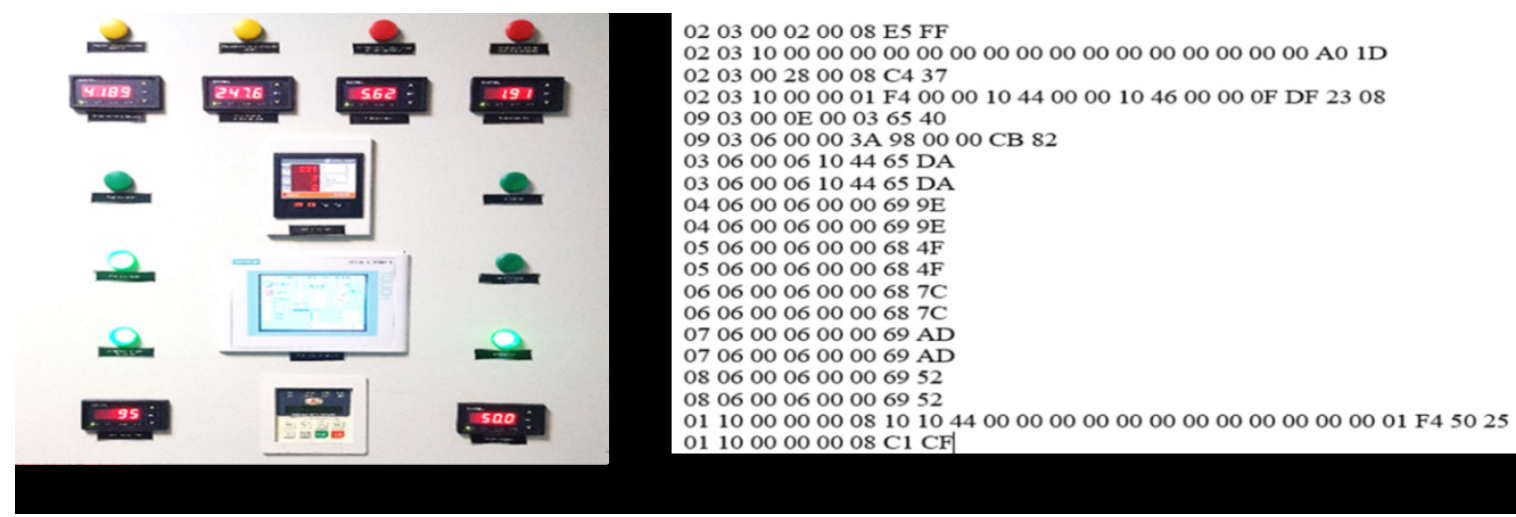

Figure 8: SPC functioning test: a) parametric values display; b)data transmission to system components

\section{Conclusions}

(SPC) RS485/RS422 communication interface prototype was intended for lowering response time at monitoring systems with programmable controllers. Its main function is to take over some of the tasks of PLC, such as transmitting data to the display unit. Integrated into monitoring system, the interface responded well at functioning tests.

\section{References}

[1] Stroia M.D.,Anghel-Drugarin C. V., Issues of semi-automatic air processing using a DCS system, Scientific Conference SysStruc 2017, pp 380-385, Resita, Romania, 2017. 
[2] Novăcescu F., Haţiegan C., Răduca M., Răduca E., Pop N., Nedeloni M., A New Method for Testing the No-Load Work of an Electric One-Phase Transformer Using The Graphical Programming, Scientific Bulletin of "Politehnica" University of Timişoara, vol. 57 (71) 2, 2012.

[3] Răduca E., PăunA. F., Răduca M., Haţiegan C., Drăghici S, Rudolf C., Candea L., Command and Running of an Experimental Model Vehicle for Covering a Labyrinth Type Runway, Analele Universităţii "Eftimie Murgu", Fascicula de Inginerie, Anul XXI, Nr. 2, Reşiţa, 2014.

[4] Stroia M.D., Derbac D., Hațiegan C., Cîndea L., Thermostat model with Arduino Uno board for controlling a cooling system, Scientific Conference Confereng 2018,pp. 7377, TârguJiu, November 2018.

[5] Jurcu M., Pădureanu I., PadeanuL., Augustinov L., Haţiegan C., Tests Regarding the Transitory Regimes of Putting off Load of the Hydroagregate, Analele Universităţii "Eftimie Murgu", Anul XXII, Issue 2, Reşiţa, 2015.

[6] Pădureanu I., Jurcu M., Augustinov L., Haţiegan C.,Răduca E., Padeanu L., Optimisation of the Start-up and Operation Regimes of Cooling Water Pumps of a High-Power Hydro Generator, Analele Universităţii "Eftimie Murgu", Anul XXII, Issue 1, Reşiţa, 2015.

[7] Pădureanu I., Jurcu M., Augustinov L., Haţiegan C., Răduca E., Implementation of an Automatic System for the Monitoring of Start-up and Operating Regimes of the Cooling Water Installations of a Hydro Generator, Analele Universităţii "Eftimie Murgu", Anul XXII, Issue 1, Reşiţa, 2015.

[8] https://rahim-soft.co/autodesk-eagle-premium-8-0-1-free-download/

[9] Răduca E., Schmidt M., Ungureanu-AnghelD., Răduca M., Haţiegan C., Nicolina Pop, Florica Novăcescu, The command of the Flour Transport Pumps in a Cereal Mill with PLC Siemens S7-1200, Analele Universităţii "Eftimie Murgu", Fascicula de Inginerie, Anul XXI, Nr. 2, Reşiţa, 2014.

[10] https://www.elektormagazine.com/news/flowcode-8-visual-programming-for-picarduino-and-arm

[11] Anghel-Drugarin C. V.,Stroia M.D., Draghici Silviu, Method For Programming An Autonomous Vehicle Using PIC $16 F 877$ Microcontroller, International ConferenceICTIC 2014, At Žilina, Slovakia,23 - 27March, 2014.

[12] Răduca E., Lucian Nistor, Haţiegan C., ., Răduca M.,Pădureanu I., Draghici S., Web server for command, control and monitoring of industrial equipment, Advanced Topics in Electrical Engineering (ATEE), 2015 9th International Symposium on, 7-9 May Bucharest, 2015.

[13] Anghel-Drugarin C. V.,Stroia M.D., Draghici S., Relative Research Upon Data Transmission Channels, The 2nd year of Global Virtual Conference, April, 7-11.2014.

[14] https://html.alldatasheet.com/html-pdf/192858/TI/75176B/23/1/75176B.html 